\title{
Japanese Comparatives Are Semantically Conjuncts: A Dynamic View*
}

\author{
Takeo Kurafuji \\ Ritsumeikan University
}

\begin{abstract}
This paper develops a differential-based semantics of comparatives, arguing that no generalized-quantifier-type degree operator is involved in Japanese comparatives, and the yori 'than'-clause introduces a degree variable, which is dynamically bound by the existential quantifier associated with a differential in the main clause. This approach accounts for the Japanese stacking comparative such as ' $\mathrm{A}$ is fat(ter) than $\mathrm{B}$ is fat than $\mathrm{C}$ is fat(ter) than $\mathrm{D}$ is fat than $\mathrm{E}$ is fat(ter) than $\mathrm{D}$ is fat,' meaning [the difference between A's fatness and B's fatness] $>$ [the difference between C's fatness and D's fatness] $>$ [the difference between E's fatness and F's fatness].
\end{abstract}

Keywords: comparison of differences, dynamic semantics, stacking comparatives

\section{Introduction}

In usual comparatives, degrees associated with individuals are compared, and the truth conditions of sentence $A$ is taller than $B$, for instance, are: A's height $>$ B's height, or there is a degree $d$ such that A's height $=\mathrm{B}$ 's height $+d$, where $d$ denotes the difference between the two degrees. ${ }^{1}$ Comparatives are also used to compare differences.

(1) Mary swam as many more laps than Joan (swam) as Linda (swam).

(Bresnan 1973: 341)

(2) John is (much) taller than Mary than Bill is. (Bhatt and Pancheva 2004: 4)

(1) means that Mary surpassed Joan in the number of swimming laps, and so did Linda, and the difference between the numbers of laps of Mary's swimming and of Joan's swimming was almost the same as the difference between the numbers of laps of Linda's and Joan's. Likewise (2) is interpreted as 'John is taller than

* I would like to thank SALT 21 reviewers and participants for their useful comments and suggestions.

1 Throughout the present paper, I use the function ' + ' in a very naïve sense without giving a formal definition.

(C)2011 Takeo Kurafuji 
Takeo Kurafuji

Mary and so is Bill, and the difference between John's height and Mary's height is greater than the difference between Bill's height and Mary's height.'

Japanese also has comparatives of differences. ${ }^{2,3}$

$\begin{array}{ccc}\text { [Chris-ga David-yori(mo) futot-tei-ru]-yori(mo), } & \text { Andy-wa } \\ \text {-NOM } & \text {-than } & \text { get.fat-PROG-PRES-than } \\ \text { Bill-yori(mo) } & \text { futot-tei-ru. } & \text {-TOP } \\ \text {-than } & \text { get.fat-PROG-PRES }\end{array}$

'Andy is fatter than Bill, and Chris is fatter than David, and the difference between Andy's fatness and Bill's fatness is greater than the difference between Chris' fatness and David's fatness.'

The language has no comparative morpheme, and a simple comparative sentence like $A$ is fatter than $B$ is expressed as 'A is fat than B.' In (3), the embedded comparative clause 'Chris is fat than David' is headed by yori(mo) 'than' and adjoins to the matrix comparative. The whole sentence compares the extent to which Andy's fatness exceeds Bill's fatness with the extent to which Chris's fatness exceeds David's fatness.

Interestingly enough, another comparative clause can be adjoined to the em-

2 Almost certainly, yori and yorimo are allomorphs. In the present paper, yori is used, but yorimo is alternatively usable. The successive use of yorimo makes the sentence slightly degraded, however.

3 Instead of typical Japanese adjectives such as taka(i) 'tall/high', I use the verbal predicate futot-tei, where the root verb is futo(r) 'get.fat' and the progressive morpheme -tei denotes the result state, and the verbal complex means 'being fat.' The reason why I do not use typical adjectives is that they are difficult, if not completely impossible, to use in the complement position of yori. Incidentally note that Beck, Oda and Sugisaki (2004) argue with examples like (i) that Japanese lacks comparative subdeletion, and claim that the language does not have binding of degree variables in the syntax.

(i)

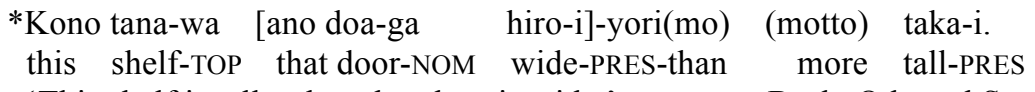
'This shelf is taller than that door is wide.'

Beck, Oda and Sugisaki (2004: 290)

The ungrammaticality of (i) might be due to another factor, however, for if a verbal predicate is used instead, we can make a subdeletion sentence like (ii).

$$
\begin{aligned}
& \text { ?Kono zubon-wa [John-ga futot-tei-ru]-yori zutto ooki-i. } \\
& \text { this trouser-TOP -NOM get.fat-PROG-PRES-than much big-PRES } \\
& \text { 'This pair of trousers is much bigger than John is fat.' }
\end{aligned}
$$

As discussed in section 3, the present study is along the same line with Beck et al.'s approach in that Japanese has no degree operator movement in syntax, but it is not necessarily the reason of the ungrammaticality of (i). My tentative speculation is that the adjective-yori sequence is filtered out for some surface reason. 
Japanese comparatives are conjuncts

bedded comparative clause as in (4), which is structured as in (5). ${ }^{4}$
[[Eric-ga Frank-yori futot-tei-ru]-yori, Chris-ga David-yori -NOM -than get.fat-PROG-PRES-than -NOM -than futot-tei-ru]-yori, Andy-wa Bill-yori futot-tei-ru. get.fat-PROG-PRES-than -TOP -than get.fat-PROG-PRES '[the difference between A's fatness and B's fatness] > [the difference between C's fatness and D's fatness] > [the difference between E's fatness and F's fatness]'

(5)

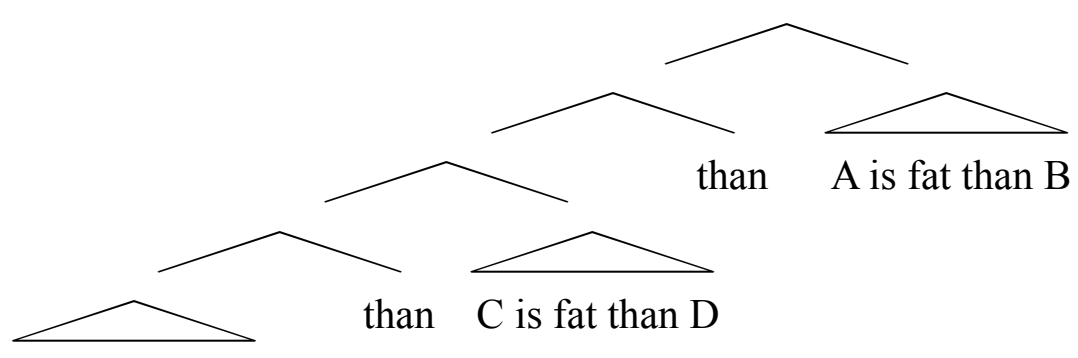

$\mathrm{E}$ is fat than $\mathrm{F}$

The sentence might sound strange, but it improves when the yori before Andy is stressed, followed by an intonation break. As the translation given in (4) shows, the sentence means that Andy, Chris, and Eric outweigh Bill, David, and Frank, respectively, and the difference between A's fatness and B's fatness is greater than the other two differences, and the difference between E's fatness and F's fatness is the least.

Stacking comparatives like (5) are impossible in English, as shown in (6), the intended interpretation of which is ' $\mathrm{A}$ is taller than $\mathrm{B}, \mathrm{C}$ is taller than $\mathrm{B}, \mathrm{D}$ is taller than $\mathrm{B}$, and the difference between A's height and B's height is greater than the difference between C's height and B's height, and the latter difference is greater than the difference between D's height and B's height.'

*A is (much) taller than $\mathrm{B}$ than $\mathrm{C}$ is than $\mathrm{D}$ is.

The immediate questions that arise are how stacking comparatives like (3) and (4) are computed, and why (6) is impossible.

In order to account for stacking comparatives like (3) and (4), I would like to

4 Structure (5) is not very precise. (4) contains the topic phrase 'Andy-Topic', which is generated above IP. The yori 'than'-clause before $A$, thus, should be assumed to adjoin to the top-most IP/CP. Since the semantic contribution of the topic marker is ignored throughout this paper, this point is not important. 
propose in section 3 that Japanese clausal comparatives are semantically conjuncts: the matrix and the embedded comparatives are combined by conjunction. It follows from this that the comparative-clause-stacking is recursively possible. I would also like to propose that clause-taking yori introduces a degree variable, which is, in the dynamic fashion, bound by the existential quantifier associated with a differential in the higher comparative clause. The ungrammaticality of English sentences like (6) is discussed in section 4, where following Heim's (2006) analysis that the comparative operator -er is a generalized quantifier, I would like to suggest that a structural parallel be required between the restrictive clause and the nuclear scope.

\section{Yori, izyooni and their clausal complements}

Japanese has two types of than: yori and izyooni, both of which can take either a phrasal or a clausal complement. Stacking comparatives like (3) and (4) are also possible with izyooni. Examples in (7) basically mean that Andy is fatter than Bill, but there is a difference between izyooni and yori. As Hayashishita (2007) points out, the truth of the complement of izyooni is entailed. In (7b) and (7d), that Bill is fat is entailed, while (7a) is interpreted just like the English counterpart.

(7) a. Phrasal yori: no entailment.

$$
\begin{array}{rrr}
\text { Andy-ga } & \text { Bill-yori } & \text { futot-tei-ru. } \\
\text {-NOM } & \text {-than } & \text { get.fat-PROG-PRES }
\end{array}
$$

b. Phrasal izyooni: That Bill is fat is entailed.

$$
\begin{array}{ccl}
\text { Andy-ga } & \text { Bill-izyooni } & \text { futot-tei-ru. } \\
\text {-NOM } & \text {-than } & \text { get.fat-PROG-PRES }
\end{array}
$$

c. Clausal yori: That Bill is fat is entailed.
[Bill-ga futot-tei-ru]-yori
Andy-ga futot-tei-ru.
-NOM get.fat-PROG-PRES-than -NOM get.fat-PROG-PRES

d. Clausal izyooni: That Bill is fat is entailed.

[Bill-ga futot-tei-ru]-izyooni Andy-ga futot-tei-ru. -NOM get.fat-PROG-PRES-than -NOM get.fat-PROG-PRES

Hayashishita (2007) analyzes the izyooni comparative as a case of comparative of deviation (COD) in the sense of Kennedy (2001), and (7b) and (7d) are paraphrased as 'Bill's fatness is greater than the contextually specified value $c$, and Andy's fatness is also greater than $c$, and the difference between Andy's fatness 
Japanese comparatives are conjuncts

and $c$ is greater than the difference between Bill's and c.' Assuming that a phrasal complement is dealt with as clausal in LF, he defines the denotation of $i z y o o n i$ as $\lambda \mathrm{P}_{<d t>} \lambda \mathrm{Q}_{<d t>}(\operatorname{Max}(\mathrm{Q})>\operatorname{Max}(\mathrm{P}))$, where $\mathrm{P}$ and $\mathrm{Q}$ are the set of degrees denoted by the embedded and the matrix clauses, respectively.

Interestingly, when yori takes a clausal complement, the entailment that Bill is fat also obtains, as in (7c). This leads to the conclusion that the phrasal complement of yori in (7a) is not derived from the clausal one in $(7 \mathrm{c})$ via deletion or the like. ${ }^{5}$ The fact that both (7c) and (7d) have the entailment suggests that the degree predicate in the clausal complement has the pos-head, which introduces the contextually specified standard, just like 'bare' degree expressions. Hayashishita's COD analysis thus can be extended to cases like (7c), but I will propose a different definition of clause-taking yori/izyooni, since his definition cannot be used for stacking comparative examples.

\section{A dynamic semantics for Japanese comparatives}

\subsection{Outline}

Following Hayashishita's COD analysis, the truth conditions of the matrix and embedded clauses in (7c) are represented as in (8a) and (8b), respectively. (8a) states that there is a difference $\mathrm{d}_{4}$ such that Andy's fatness is greater than the contextually specified value $\mathrm{d}_{c}$ by $\mathrm{d}_{4}$, and ditto with ( $8 \mathrm{~b}$ ).

$$
\begin{array}{lll}
\text { a. } & \text { matrix clause: } & \left.\exists \mathrm{d}_{4} \text { [Andy's fatness }=\mathrm{d}_{c}+\mathrm{d}_{4}\right] \\
\text { b. } & \text { embedded clause: } & \left.\exists \mathrm{d}_{2} \text { [Bill's fatness }=\mathrm{d}_{c}+\mathrm{d}_{2}\right]
\end{array}
$$

The truth conditions of (7c) that I would like to propose are (9), which is read as: Andy's fatness is greater than $\mathrm{d}_{c}$ by $\mathrm{d}_{4}$, and that difference, $\mathrm{d}_{4}$, is greater than the maximal value of the difference between Bill's fatness and $d_{c}$ by $d_{3}$.

(9) $\exists d_{4}\left[\right.$ Andy's fatness $\left.=d_{c}+d_{4}\right] \wedge$

$$
\exists \mathrm{d}_{3}\left[\mathrm{~d}_{4}=\max \left(\lambda \mathrm{d}_{2}\left[\text { Bill's fatness }=\mathrm{d}_{c}+\mathrm{d}_{2}\right]\right)+\mathrm{d}_{3}\right]
$$

There are two important points here. First, (9) has a conjunction structure,

5 I do not discuss so-called reduced phrasal yori as (i), where the complement of yori is dativemarked. See Bhatt and Takahashi (2008) for relevant discussions.

(i) John-ga [Sue-ni]-yori Mary-ni ooku-no hon-o age-ta. -NOM -DAT-than -DAT many-GEN book-ACC give-PAST 'John gave more books to Mary than to Sue.' 
where '[John's fatness $\left.=\mathrm{d}_{c}+\mathrm{d}_{3}\right]$ ' and '[Mary's fatness $=\mathrm{d}_{c}+\mathrm{d}_{2}$ ]' correspond to the matrix and the embedded sentences, respectively. This amounts to saying that comparative clauses are conjuncts in semantics. Second, the semantics of yori has a large contribution. Roughly, it translates into ' $\exists \mathrm{d}_{4}\left[\mathrm{~d}_{3}=\max (\ldots)+\mathrm{d}_{4}\right]$ ', where a new differential $\mathrm{d}_{4}$ is introduced. This means that whenever you use (clausal) yori, you get a difference. The degree variable $\mathrm{d}_{4}$ is bound by the existential quantifier associated with the matrix clause. This is guaranteed by assuming that yori itself has an index. In this regard, yori is anaphoric. Other necessary tools come from dynamic semantics, which will be given in the next subsection.

\subsection{Formal devices and derivation}

In this paper I assume, using Chierchia's (1995) dynamic semantics, that dynamic binding applies to degree variables as well as individuals. ${ }^{6}$ Thus (10) holds (see Appendix for the definitions of symbols). I also assume that Japanese clausal comparatives are represented as conjuncts as in (11).

$$
\begin{aligned}
& \exists \mathrm{J}[\uparrow \phi] \wedge \uparrow \psi=\underline{\exists} \mathrm{d}[\uparrow \phi \underline{\wedge} \uparrow \psi] \\
& \|[\mathrm{B}]-\text { yori } \mathrm{A} \|
\end{aligned}
$$

Ignoring the compositional semantics of the verb and the progressive morpheme (see footnote 3 ), the gradable predicate futot-tei is assumed to translate into $\delta_{\text {fat }}$ of type $<e, d>$.

\subsubsection{Absolute constructions: $\mathrm{A}-\mathbf{d}_{\boldsymbol{c}}$}

As argued in von Stechow 1984, Klein 1991, and Kennedy 2007 among others, the contextually specified value of a standard of comparison is provided by the null morpheme pos. In the dynamic setting, I define pos as follows.

$$
\left\|p o s_{\mathrm{n}}\right\|={ }_{\text {def }} \lambda \mathrm{g} \lambda \times \underline{\exists} \mathrm{d}_{\mathrm{n}}\left[\uparrow \mathrm{g}(\mathrm{x})=\mathrm{d}_{c}+\mathrm{d}_{\mathrm{n}}\right]
$$

The null morpheme pos is indexed, indicating the difference between the object's degree and the standard.

With this, the truth conditions of the absolute sentence Andy-ga futotteiru 'Andy is fat' are represented as in (13), which is read: there is a differential

6 There are some precursors applying dynamic views to the semantics of degree expressions such as Barker 2002 and Brasoveanu 2008. 
Japanese comparatives are conjuncts

degree $d_{2}$ such that Mary's fatness is greater than the contextually specified value $\mathrm{d}_{c}$ by $\mathrm{d}_{2}$.

(13) $\|$ Andy-ga futotteiru-pos $2 \| \sim \sim \exists \mathrm{J}_{2}\left[\uparrow \delta_{\text {fat }}(\mathrm{a})=\mathrm{d}_{c}+\mathrm{d}_{2}\right]$

\subsubsection{Phrasal comparatives: A - B}

DP-taking yori is defined as (14), and a comparative sentence like Andy-ga Bill-yori futotteiru 'Andy is fatter than Bill' is represented as in (15). ${ }^{7}$

(14) DP-taking yori:

$\|$ yori $_{n} \|=_{\text {def }} \lambda y \lambda g \lambda x \underline{\exists} \mathrm{d}_{\mathrm{n}}\left[\uparrow \mathrm{g}(\mathrm{x})=\mathrm{g}(\mathrm{y})+\mathrm{d}_{\mathrm{n}}\right]$

(15) $\|$ Andy-ga Bill-yori ${ }_{2}$ futtoteiru $\| \sim \sim \exists \mathrm{d}_{2}\left[\uparrow \delta_{\text {fat }}(\mathrm{a})=\delta_{\text {fat }}(\mathrm{b})+\mathrm{d}_{2}\right]$

Like the definition of pos, the index on yori indicates an existentially bound difference.

\subsubsection{Clausal comparatives: $\left(A-d_{c}\right)>\left(B-d_{c}\right)$}

Let us consider how the logical representation of (7c), repeated as (16), is derived.

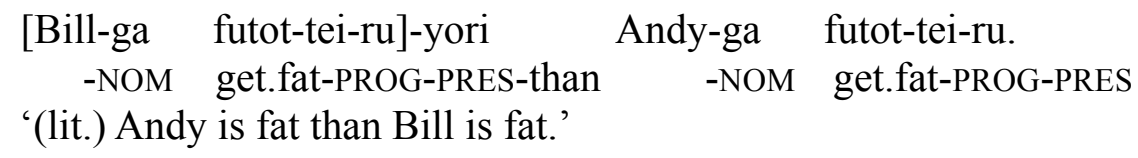

As defined in (17), clause-taking yori introduces a degree discourse marker. The index $m$ that the degree discourse marker bears is superscripted on yori.

(17) Clause-taking yori $_{\mathrm{n}}{ }^{\mathrm{m}}$ :

$\|$ yori ${ }_{n}{ }^{m} \|={ }_{\text {def }} \lambda P \underline{\exists} \mathrm{d}_{\mathrm{n}}\left[\uparrow \mathrm{d}_{\mathrm{m}}=\max (\downarrow \mathrm{P})+\mathrm{d}_{\mathrm{n}}\right], \mathrm{d}_{\mathrm{m}}$ is a discourse marker of type $d$, and $\mathrm{P}$ is a set of degrees of type $\langle d, c c>$.

The truth conditions of the embedded absolute expression in (16) are $\exists d_{2}\left[\uparrow \delta_{\text {fat }}(a)\right.$ $=\mathrm{d}_{c}+\mathrm{d}_{2}$ ] of type $c c$. This combines with yori, but the function 'max' in (17) requires a dynamic version of a set of degrees of type $\langle d, c c\rangle$, so the embedded CCP must be shifted. This type shifting is carried out by Dekker's (1993)

7 The definition of the DP-taking izyooni should be different from (14) because of the presence of entailment. The entailment part is easily incorporated as in $\lambda y \lambda g \lambda x \underline{\exists} d_{n}\left[\uparrow g(x)=g(y)+d_{n} \wedge\right.$ $\left.\uparrow \mathrm{g}(\mathrm{y})>\mathrm{d}_{c}\right]$. 
Existential Disclosure (ED) given in (18). The resulting representation (19) then combines with yori, as in (20).

(18) Existential Disclosure (ED): For any discourse marker $\alpha_{\mathrm{n}}$ and CCP A, $\underline{\lambda} \alpha_{\mathrm{n}} \mathrm{A}=\lambda \mathrm{u}\left[\mathrm{A} \underline{\Lambda} \uparrow \alpha_{\mathrm{n}}=\mathrm{u}\right]$

(19) $\lambda \mathrm{d}_{2}\left[\uparrow \delta_{\text {fat }}(\mathrm{b})=\mathrm{d}_{c}+\mathrm{d}_{2}\right]$

(20) $\|$ [Bill is fat 2$]$-yori ${ }^{4} \| \sim \sim>\exists \mathrm{d}_{3}\left[\uparrow \mathrm{d}_{4}=\max \left(\lambda \mathrm{d}_{2}\left[\uparrow \delta_{\text {fat }}(\mathrm{b})=\mathrm{d}_{c}+\mathrm{d}_{2}\right]\right)+\mathrm{d}_{3}\right]$

The matrix clause of (16) translates just like (13), and conjoins with (20) by (11), as in (21). This is the dynamic version of (9).

(21) $\|$ [Bill is fat-pos 2$]$-yori ${ }^{4}$ Andy is fat-pos $4 \| \sim \sim>$ $\exists \mathrm{d}_{4}\left[\uparrow \delta_{\mathrm{fat}}(\mathrm{a})=\mathrm{d}_{c}+\mathrm{d}_{4}\right] \quad \underline{\wedge} \quad \exists \mathrm{d}_{3}\left[\uparrow \mathrm{d}_{4}=\max \left(\lambda \mathrm{d}_{2}\left[\uparrow \delta_{\text {fat }}(\mathrm{b})=\mathrm{d}_{c}+\mathrm{d}_{2}\right]\right)+\mathrm{d}_{3}\right]$

$=\underline{\exists} \mathrm{d}_{4} \underline{\exists} \mathrm{d}_{3}\left[\uparrow \delta_{\text {fat }}(\mathrm{a})=\mathrm{d}_{c}+\mathrm{d}_{4} \underline{\Lambda} \uparrow \mathrm{d}_{4}=\max \left(\lambda \mathrm{d}_{2}\left[\uparrow \delta_{\mathrm{fat}}(\mathrm{b})=\mathrm{d}_{c}+\mathrm{d}_{2}\right]\right)+\mathrm{d}_{3}\right]$

By dynamic biding in (10), the degree variable $\mathrm{d}_{4}$ in the second conjunct is dynamically bound by the existential quantifier associated with the difference between Andy's fatness and the standard value given in context.

A SALT 21 reviewer casts a doubt on the COD analysis like (21), for the truth conditions predict that (16) can be true in the context where Bill's actual weight exceeds Andy's since nothing guarantees that the matrix and subordinated clauses share the same standard value. I think this prediction is actually borne out, contrary to the reviewer's skepticism. Suppose that Andy is a 10-year-old boy and Bill is an adult man, and Bill is slightly fatter than the average adult man, but Andy's obesity is much greater than the average weight of boys of age 10 . In this context, (16) can be felicitously uttered.

\subsubsection{Stacking comparatives: $\left(A-d_{c}\right)>\left(B-d_{c}\right)>\left(C-d_{c}\right)$}

Another absolute expression can be added to the embedded sentence in (16). ${ }^{8}$

8 When an intonation break is present before Bill, the two embedded clauses are interpreted as being juxtaposed, as '(lit.) Andy is fat [than Bill is fat] or [than Chris is fat].' 
Japanese comparatives are conjuncts

$\begin{array}{clll}{[[C h r i s-g a} & \text { futot-tei-ru]-yori } & {[\text { Bill-ga }} & \text { futot-tei-ru]]-yori } \\ \text {-NOM } & \text { get.fat-PROG-PRES-than } & \text {-NOM } & \text { get.fat-PROG-PRES-than } \\ \text { Andy-ga } & \text { futot-tei-ru. } & & \\ \text {-NOM } & \text { get.fat-PROG-PRES }\end{array}$
'(lit.) Andy is fat [than Bill is fat [than Chris is fat]].'

The sentence means that Andy is fatter than Bill and Bill is fatter than Chris, and they are all fat. The logical representation of (22) easily obtains by ED and dynamic binding, as illustrated in (23).

(23) a. \|[Chris is fat-pos 2$]-$ yori $^{4}$ Bill is fat-pos $s_{4} \| \sim \sim>$

$$
\underline{\exists} \mathrm{d}_{4} \exists \mathrm{d}_{3}\left[\uparrow \delta_{\mathrm{fat}}(\mathrm{b})=\mathrm{d}_{c}+\mathrm{d}_{4} \wedge \uparrow \mathrm{d}_{4}=\max \left(\lambda \mathrm{d}_{2}\left[\uparrow \delta_{\mathrm{fat}}(\mathrm{c})=\mathrm{d}_{c}+\mathrm{d}_{2}\right]\right)+\mathrm{d}_{3}\right]
$$

b. ED applies to $\exists \mathrm{d}_{4}$, the difference between Bill's fatness and $\mathrm{d}_{c}$.

$$
\lambda \mathrm{d}_{4} \exists_{\mathrm{d}_{3}}\left[\uparrow \delta_{\mathrm{fat}}(\mathrm{b})=\mathrm{d}_{c}+\mathrm{d}_{4} \underline{\uparrow} \uparrow \mathrm{d}_{4}=\max \left(\lambda \mathrm{d}_{2}\left[\uparrow \delta_{\mathrm{fat}}(\mathrm{c})=\mathrm{d}_{c}+\mathrm{d}_{2}\right]\right)+\mathrm{d}_{3}\right]
$$

c. $\quad \|\left[[C h r i s\right.$ is fat-pos 2$]$-yori ${ }_{3}^{4}$ Bill is fat-pos 4$]$-yori ${ }_{5}{ }^{6} \| \sim \sim>$

$$
\begin{array}{r}
\underline{\exists} \mathrm{d}_{5}\left[\uparrow \mathrm{d}_{6}=\max \left(\lambda \mathrm { d } _ { 4 } \underline { \exists } _ { 3 } \left[\uparrow \delta_{\mathrm{fat}}(\mathrm{b})=\mathrm{d}_{c}+\mathrm{d}_{4} \wedge\right.\right.\right. \\
\left.\left.\left.\uparrow \mathrm{d}_{4}=\max \left(\lambda \mathrm{d}_{2}\left[\uparrow \delta_{\mathrm{fat}}(\mathrm{c})=\mathrm{d}_{c}+\mathrm{d}_{2}\right]\right)+\mathrm{d}_{3}\right]\right)+\mathrm{d}_{5}\right]
\end{array}
$$

d. || [[Chris is fat-pos $\left.{ }_{2}\right]$-yori ${ }_{3}^{4}$ Bill is fat-pos 4$]-$ yori $_{5}{ }^{6}$

$$
\begin{array}{r}
\underline{\exists} \mathrm{d}_{6} \underline{\exists} \mathrm{d}_{5}\left[\uparrow \delta_{\mathrm{fat}}(\mathrm{a})=\mathrm{d}_{c}+\mathrm{d}_{6}\right. \\
\uparrow \mathrm{d}_{6}=\max \left(\lambda \mathrm { d } _ { 4 } \exists \mathrm { d } _ { 3 } \left[\uparrow \delta_{\text {fat }}(\mathrm{b})=\mathrm{d}_{c}+\mathrm{d}_{4} \Lambda\right.\right. \\
\left.\left.\left.\uparrow \mathrm{d}_{4}=\max \left(\lambda \mathrm{d}_{2}\left[\uparrow \delta_{\mathrm{fat}}(\mathrm{c})=\mathrm{d}_{c}+\mathrm{d}_{2}\right]\right)+\mathrm{d}_{3}\right]\right)+\mathrm{d}_{5}\right]
\end{array}
$$

Andy is fat-pos $6 \| \sim>$

(23d) says that Andy's fatness is greater than $d_{c}$ by $d_{6}$, and $d_{6}$ is greater than the maximal difference between Bill's fatness and $d_{c}$. This amounts to saying that Andy is fatter than Bill. The relation between Bill's and Chris's fatnesses in the embedded clause is also represented in the same way in (23d).

\subsubsection{Clausal comparatives: $(A-B)>(C-D)$}

Now let us move to (3), repeated as (24), where both the matrix and the embedded clauses are comparatives. 
(24)
[Chris-ga David-yori
futot-tei-ru]-yori,
Andy-wa
-NOM -than
get.fat-PROG-PRES-than
-TOP
Bill-yori futot-tei-ru.
-than get.fat-PROG-PRES
'(lit.) Andy is fat than Bill [than [Chris is fat than David]].'

The logical representation of (24) obtains through the following steps.

(25) a. $\quad \|$ David-yori ${ }_{2}$ Chris is fat $\| \sim \sim \quad \exists \mathrm{d}_{2}\left[\uparrow \delta_{\text {fat }}(\mathrm{c})=\delta_{\text {fat }}(\mathrm{d})+\mathrm{d}_{2}\right]$

b. $\quad E D: \lambda d_{2}\left[\uparrow \delta_{\text {fat }}(c)=\delta_{\text {fat }}(d)+d_{2}\right]$

c. $\quad \mid\left[\right.$ David-yori ${ }_{2}$ Chris is fat $]-$ yori $_{3}{ }^{4} \| \sim \sim>$

$$
\underline{\exists} \mathrm{d}_{3}\left[\uparrow \mathrm{d}_{4}=\max \left(\lambda \mathrm{d}_{2}\left[\uparrow \delta_{\mathrm{fat}}(\mathrm{c})=\delta_{\text {fat }}(\mathrm{d})+\mathrm{d}_{2}\right]\right)+\mathrm{d}_{3}\right]
$$

d. $\quad \|$ Bill-yori 4 Andy is fat $\| \sim \sim>\quad \exists \mathrm{d}_{4}\left[\uparrow \delta_{\text {fat }}(\mathrm{a})=\delta_{\text {fat }}(\mathrm{b})+\mathrm{d}_{4}\right]$

e. $\|\left[\right.$ David-yori ${ }_{2}$ Chris is fat]-yori ${ }_{3}{ }^{4} \quad$ [Bill-yori ${ }_{4}$ Andy is fat $] \| \sim>$ $(25 \mathrm{~d}) \wedge(25 \mathrm{c})$

$$
\begin{aligned}
& =\underline{\exists} \mathrm{d}_{4}\left[\uparrow \delta_{\text {fat }}(\mathrm{a})=\delta_{\mathrm{fat}}(\mathrm{b})+\mathrm{d}_{4}\right] \underline{\Lambda} \\
& \underline{\exists} \mathrm{d}_{3}\left[\uparrow \mathrm{d}_{4}=\max \left(\lambda \mathrm{d}_{2}\left[\uparrow \delta_{\mathrm{fat}}(\mathrm{c})=\delta_{\mathrm{fat}}(\mathrm{d})+\mathrm{d}_{2}\right]\right)+\mathrm{d}_{3}\right] \\
& =\underline{\exists} \mathrm{d}_{4} \underline{\exists} \mathrm{d}_{3}\left[\uparrow \delta_{\text {fat }}(\mathrm{a})=\delta_{\mathrm{fat}}(\mathrm{b})+\mathrm{d}_{4} \underline{\Lambda}\right. \\
& \left.\uparrow \mathrm{d}_{4}=\max \left(\lambda \mathrm{d}_{2}\left[\uparrow \delta_{\text {fat }}(\mathrm{c})=\delta_{\mathrm{fat}}(\mathrm{d})+\mathrm{d}_{2}\right]\right)+\mathrm{d}_{3}\right]
\end{aligned}
$$

First, as shown in 3.2.2, the comparative with DP-taking yori is represented as in (25a). To combine with clause-taking yori, ED applies, and then the resulting representation combines with the yori as in (23c). The matrix clause is also represented as in (25d). (25d) and (25c) are dynamically conjoined, yielding the final representation in (25e), which correctly states that the difference between Andy's fatness and Bill's fatness, $\mathrm{d}_{4}$, is greater than the maximal difference between Chris's fatness and David's fatness by $d_{3}$.

\subsubsection{Stacking comparatives: $(A-B)>(C-D)>(E-F)$}

Recursive applications of ED and dynamic binding also derive logical representations of stacking comparatives like (4), repeated as (26). 
Japanese comparatives are conjuncts

(26)

\begin{tabular}{ccccr} 
[[Eric-ga & Frank-yori & futot-tei-ru]-yori, & \multicolumn{1}{c}{ Chris-ga } & David-yori \\
-NOM & -than & get.fat-PROG-PRES-than & -NOM & -than \\
futot-tei-ru]-yori, & Andy-wa & Bill-yori & futot-tei-ru. & \\
get.fat-PROG-PRES-than & -TOP & -than & get.fat-PROG-PRES
\end{tabular}
'(lit.) Andy is fat than Bill [than [Chris is fat than David [than [Eric is fat than Frank]]]].'

The embedded clausal comparative 'Chris is fat than David [than [Eric is fat than Frank]]' is processed in the same way as (24) is.

(27) $\|\left[\right.$ Frank-yori ${ }_{2}$ Eric is fat $]$-yori ${ }_{3}{ }^{4}$ [David-yori 4 Chris is fat $] \| \sim>$ $\underline{\exists} \mathrm{d}_{4} \underline{\exists} \mathrm{d}_{3}\left[\uparrow \delta_{\text {fat }}(\mathrm{c})=\delta_{\mathrm{fat}}(\mathrm{d})+\mathrm{d}_{4} \underline{\Lambda} \uparrow \mathrm{d}_{4}=\max \left(\lambda \mathrm{d}_{2}\left[\uparrow \delta_{\mathrm{fat}}(\mathrm{e})=\delta_{\mathrm{fat}}(\mathrm{f})+\mathrm{d}_{2}\right]\right)+\mathrm{d}_{3}\right]$

The existential quantifier binding $\mathrm{d}_{4}$ is wiped off by $\mathrm{ED}$, and combines with clause-taking yori, resulting in (28a). As illustrated in (28c), this is dynamically conjoined with the matrix comparative 'Andy is fat than Bill' in (28b).

(28) a. \| [[Frank-yori ${ }_{2}$ Eric is fat $]-$ yori $_{3}{ }^{4}\left[\right.$ David-yori ${ }_{4}$ Chris is fat $\left.]\right]-y o r i_{5}{ }^{6} \|$

$\sim \sim \underline{\exists}_{5}\left[\uparrow \mathrm{d}_{6}=\max \left(\lambda \mathrm{d}_{4} \underline{\underline{ }} \mathrm{d}_{3}\left[\uparrow \delta_{\mathrm{fat}}(\mathrm{c})=\delta_{\mathrm{fat}}(\mathrm{d})+\mathrm{d}_{4} \underline{\Lambda}\right.\right.\right.$

$$
\left.\left.\left.\uparrow \bar{d}_{4}=\max \left(\lambda \mathrm{d}_{2}\left[\uparrow \delta_{\text {fat }}(e)=\delta_{\text {fat }}(\mathrm{f})+\mathrm{d}_{2}\right]\right)+\mathrm{d}_{3}\right]\right)+\mathrm{d}_{5}\right]
$$

b. $\quad \|$ Bill-yori $_{6}$ Andy is fat $\| \sim \sim>\quad \exists \mathrm{d}_{6}\left[\uparrow \delta_{\text {fat }}(\mathrm{a})=\delta_{\text {fat }}(\mathrm{b})+\mathrm{d}_{6}\right]$

c. $\quad(28 b) \wedge(28 \mathrm{a})$

$$
\begin{aligned}
& =\underline{\exists} \mathrm{d}_{6} \underline{\underline{ }} \mathrm{d}_{5}\left[\uparrow \delta_{\mathrm{fat}}(\mathrm{a})=\delta_{\mathrm{fat}}(\mathrm{b})+\mathrm{d}_{6} \underline{\Lambda} \uparrow \mathrm{d}_{6}=\max \left(\lambda \mathrm { d } _ { 4 } \underline { \exists } \mathrm { d } _ { 3 } \left[\uparrow \delta_{\mathrm{fat}}(\mathrm{c})=\delta_{\mathrm{fat}}(\mathrm{d})+\mathrm{d}_{4}\right.\right.\right. \\
& \left.\left.\left.\Lambda \uparrow_{4}=\max \left(\lambda \mathrm{d}_{2}\left[\uparrow \delta_{\text {fat }}(\mathrm{e})=\delta_{\text {fat }}(\mathrm{f})+\mathrm{d}_{2}\right]\right)+\mathrm{d}_{3}\right]\right)+\mathrm{d}_{5}\right]
\end{aligned}
$$

The differential variables $d_{2}, d_{4}$, and $d_{6}$ denote $\left(\delta_{\text {fat }}(e)-\delta_{\text {fat }}(f)\right),\left(\delta_{\text {fat }}(c)-\delta_{\text {fat }}(d)\right)$ and $\left(\delta_{\mathrm{fat}}(\mathrm{a})-\delta_{\mathrm{fat}}(\mathrm{b})\right)$, respectively, and $\mathrm{d}_{6}$ is greater than $\mathrm{d}_{4}$, which is greater than $d_{2}$. This correctly captures the interpretation of (26).

\subsection{More complicated cases}

Adding one more comparative to (26) gives us (29). 
(29) [Gale-ga Henry-yori futot-tei-ru]-yori, -NOM -than get.fat-PROG-PRES-than

[Eric-ga Frank-yori futot-tei-ru]-yori, -NOM -than get.fat-PROG-PRES-than

[Chris-ga David-yori futot-tei-ru]-yori, -NOM -than get.fat-PROG-PRES-than

Andy-wa Bill-yori futot-tei-ru.

-TOP -than get.fat-PROG-PRES

(30) $(\mathrm{A}-\mathrm{B})>(\mathrm{C}-\mathrm{D})>(\mathrm{E}-\mathrm{F})>(\mathrm{G}-\mathrm{H})$

Interpretation (30) is possible with (29). This reading derives when the existential quantifier associated with the difference between $\delta_{\text {fat }}(a)$ and $\delta_{\text {fat }}(b) d y-$ namically binds the degree discourse marker denoting the maximal difference between $\delta_{\text {fat }}(\mathrm{c})$ and $\delta_{\text {fat }}(\mathrm{d})$.

A SALT 21 reviewer asked whether (29) can have the interpretation in (31).

$$
((\mathrm{A}-\mathrm{B})>(\mathrm{C}-\mathrm{D}))>((\mathrm{E}-\mathrm{F})>(\mathrm{G}-\mathrm{H}))
$$

This interpretation is actually possible if the topic marker attaching to Andy is replaced with nominative -ga, and an intonation break takes place before Chris. Using an emphatic adverbial expression like sarani 'furthermore, even' before Chris makes this interpretation easier to get. The sentence is structured as in (32).

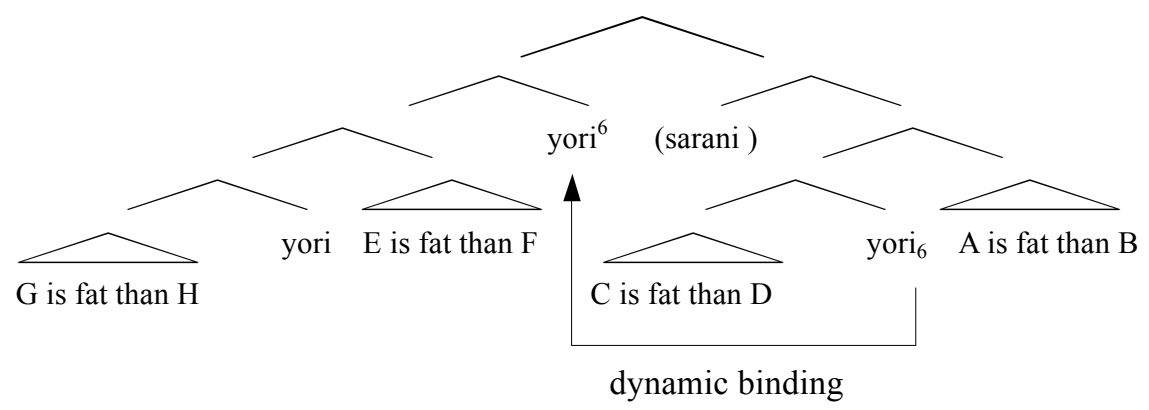

(33) a. $\|[\mathrm{G}$ is fat than $\mathrm{H}]$-yori $\mathrm{E}$ is fat than $\mathrm{F} \| \sim \sim>$ $\underline{\exists} \mathrm{d}_{4} \underline{\exists} \mathrm{d}_{3}\left[\uparrow \delta_{\mathrm{fat}}(\mathrm{e})=\delta_{\mathrm{fat}}(\mathrm{f})+\mathrm{d}_{4} \underline{\Lambda}\right.$

$$
\left.\overline{\mathrm{d}}_{4}=\max \left(\lambda \mathrm{d}_{2}\left[\uparrow \delta_{\text {fat }}(\mathrm{g})=\delta_{\text {fat }}(\mathrm{h})+\mathrm{d}_{2}\right]\right)+\mathrm{d}_{3}\right]
$$


Japanese comparatives are conjuncts

b. $\quad \|[\mathrm{C}$ is fat than $\mathrm{D}]$-yori $\mathrm{A}$ is fat than $\mathrm{B} \| \sim \sim>$

$$
\underline{\exists} \mathrm{d}_{7} \exists \mathrm{d}_{6}\left[\uparrow \delta_{\text {fat }}(\mathrm{a})=\delta_{\mathrm{fat}}(\mathrm{b})+\mathrm{d}_{7} \underline{\Lambda} \mathrm{d}_{7}=\max \left(\lambda \mathrm{d}_{5}\left[\uparrow \delta_{\text {fat }}(\mathrm{c})=\delta_{\mathrm{fat}}(\mathrm{d})+\mathrm{d}_{5}\right]\right)+\mathrm{d}_{6}\right]
$$

c. $\quad$ ED to $(33 \mathrm{a})$ :

$$
\lambda \mathrm{d}_{3} \underline{\exists}_{4}\left[\uparrow \delta_{\mathrm{fat}}(\mathrm{e})=\delta_{\mathrm{fat}}(\mathrm{f})+\mathrm{d}_{4} \frac{\Lambda}{\uparrow \mathrm{d}_{4}}=\max \left(\lambda \mathrm{d}_{2}\left[\uparrow \delta_{\mathrm{fat}}(\mathrm{g})=\delta_{\mathrm{fat}}(\mathrm{h})+\mathrm{d}_{2}\right]\right)+\mathrm{d}_{3}\right]
$$

d. $\quad \|[(33 \mathrm{c})]$-yori ${ }^{6} \| \sim \sim>$

$$
\begin{aligned}
\underline{\exists} \mathrm{d}_{8}\left[\uparrow \mathrm{d}_{6}=\max \left(\lambda \mathrm { d } _ { 3 } \underline { \exists } \mathrm { d } _ { 4 } \left[\uparrow \delta_{\mathrm{fat}}(\mathrm{e})=\delta_{\mathrm{fat}}(\mathrm{f})+\mathrm{d}_{4} \underline{\Lambda}\right.\right.\right. \\
\left.\left.\left.\uparrow \mathrm{d}_{4}=\max \left(\lambda \mathrm{d}_{2}\left[\uparrow \delta_{\mathrm{fat}}(\mathrm{g})=\delta_{\mathrm{fat}}(\mathrm{h})+\mathrm{d}_{2}\right]\right)+\mathrm{d}_{3}\right]\right)+\mathrm{d}_{8}\right]
\end{aligned}
$$

e. $\quad(33 b) \wedge(33 d)$

$$
\begin{aligned}
& \underline{\exists} \mathrm{d}_{8} \underline{\underline{ }} \mathrm{d}_{7} \underline{\underline{ }} \mathrm{d}_{6}\left[\uparrow \delta_{\text {fat }}(\mathrm{e})=\delta_{\text {fat }}(\mathrm{f})+\mathrm{d}_{7}\right. \\
& \underline{\Lambda} \uparrow \mathrm{d}_{7}=\max \left(\lambda \mathrm{d}_{5}\left[\uparrow \delta_{\mathrm{fat}}(\mathrm{g})=\delta_{\mathrm{fat}}(\mathrm{h})+\mathrm{d}_{5}\right]\right)+\mathrm{d}_{6} \\
& \underline{\wedge} \uparrow \mathrm{d}_{6}=\max \left(\lambda \mathrm { d } _ { 3 } \underline { \underline { } } \mathrm { d } _ { 4 } \left[\uparrow \delta_{\mathrm{fat}}(\mathrm{e})=\delta_{\mathrm{fat}}(\mathrm{f})+\mathrm{d}_{4}\right.\right. \\
& \left.\left.\left.\underline{\Lambda} \uparrow \mathrm{d}_{4}=\max \left(\lambda \mathrm{d}_{2}\left[\uparrow \delta_{\text {fat }}(\mathrm{g})=\delta_{\mathrm{fat}}(\mathrm{h})+\mathrm{d}_{2}\right]\right)+\mathrm{d}_{3}\right]\right)+\mathrm{d}_{8}\right]
\end{aligned}
$$

There is nothing new in translations (33a) and (33b) (see derivations in (25)). What is new here is ED. In the examples so far, ED applies to the existential quantifier associated with the matrix difference, like $\exists \mathrm{d}_{4}$ or $\exists \mathrm{d}_{7}$ in $(34 \mathrm{a}, \mathrm{b})$. As in $(33 \mathrm{c})$, it applies to $\exists \mathrm{d}_{3}$, the one associated with the difference between the matrix and the embedded clauses. The resulting representation then combines with yori ${ }^{6}$, which introduces discourse marker $\mathrm{d}_{6}$. (33d) means that $\mathrm{d}_{6}$ is greater than the $\max \left(\left(\delta_{\text {fat }}(e)-\delta_{\text {fat }}(f)\right)-\left(\delta_{\text {fat }}(g)-\delta_{\text {fat }}(h)\right)\right)$ by $d_{8}$. By dynamic binding, $d_{6}$ is bound by $\exists \mathrm{d}_{6}$, which is introduced by yori $i_{6}$, denoting a degree of $\left(\left(\delta_{\text {fat }}(\mathrm{a})-\right.\right.$ $\left.\left.\delta_{\text {fat }}(b)\right)-\left(\delta_{\text {fat }}(\mathrm{c})-\delta_{\text {fat }}(d)\right)\right)$. So, interpretation $((A-B)>(C-D))>((E-F)>(G-$ $\mathrm{H})$ ) derives by assuming nothing additional.

The fact that (32) has the reading in (33e) is very important, for it strongly suggests that dynamic binding actually works. In the examples in the previous subsections, free degree variables introduced by yori are bound by an existential quantifier in the higher clause. It might be argued, based on this fact, that those degree variables are pronominal and bound by c-commanding quantifiers. If so, it could be concluded that we do not have to adopt dynamic semantics. In (32), however, the position where a degree variable is introduced is clearly not c-commanded by the existential quantifier whose c-command domain is [Andy is fat than Bill than Chris is fat than David]. In other words, interpretations like (33e) suggest the necessity of a dynamic approach. 


\subsection{A speculation on difference-comparing comparatives in English}

Another SALT 21 reviewer happened to point out an example like (34).

(34) $\mathrm{A}$ is a greater extent more expensive than $\mathrm{B}$ than $\mathrm{C}$ is, than $\mathrm{D}$ is more expensive than $\mathrm{E}$ than $\mathrm{F}$ is.

The interpretation of this sentence is $((\mathrm{A}-\mathrm{B})>(\mathrm{C}-\mathrm{B}))>((\mathrm{D}-\mathrm{E})>(\mathrm{F}-\mathrm{E}))$, which is identical to interpretation (31) of example (29). Notice that this is a comparative denoting a difference of differences, but not a stacking comparative. As given in (6), repeated as (35), no stacking comparative is possible in English. The question is why (34) is fine while (35) is ungrammatical.

$$
\begin{aligned}
& (\mathrm{A}-\mathrm{B})>(\mathrm{C}-\mathrm{B})>(\mathrm{D}-\mathrm{B}) \\
& * \mathrm{~A} \text { is (much) taller than } \mathrm{B} \text { than } \mathrm{C} \text { is, than } \mathrm{D} \text { is. }
\end{aligned}
$$

My speculation is this. In the Bresnan-Heim analysis (Heim 2006), the -er morpheme and the than-clause make a constituent and the former is analyzed as a generalized quantifier, where the complement of than serves as restriction. Here I suppose that there is an LF condition that the restriction and the nuclear scope of the -er operator must be structurally parallel at LF. Relevant LF structures are given in (36) to (39), and in all good cases the restrictions and the nuclear scopes share the same structure, while such a parallel does not hold in the stacking case in (38).

(36) $\mathrm{A}$ is taller $\mathrm{B}$ is.

-er (B is d-tall) (A is d-tall)

(37) $\mathrm{A}$ is (much) taller than $\mathrm{B}$ than $\mathrm{C}$ is. $(\mathrm{A}-\mathrm{B})>(\mathrm{C}-\mathrm{D})$

-er (-er (B is d-tall) (C is d-tall))

(-er (B is d-tall) (A is d-tall))

(38)

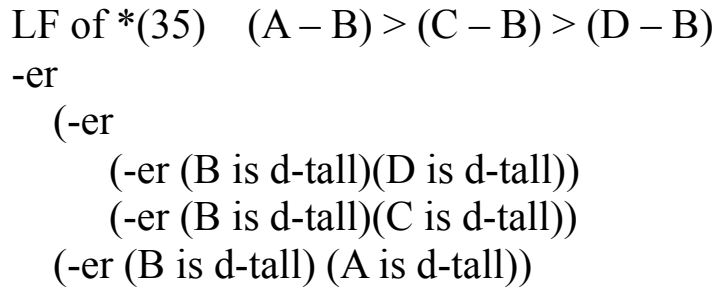


Japanese comparatives are conjuncts

(39)

$$
\begin{aligned}
& \mathrm{LF} \text { of }(34) \quad((\mathrm{A}-\mathrm{B})>(\mathrm{C}-\mathrm{B}))>((\mathrm{D}-\mathrm{E})>(\mathrm{F}-\mathrm{E})) \\
& \text {-er } \\
& \quad(-\mathrm{er} \\
& \quad(-\mathrm{er}(\mathrm{E} \text { is d-expensive })(\mathrm{F} \text { is d-expensive })) \\
& \quad(-\mathrm{er}(\mathrm{E} \text { is d-expensive })(\mathrm{D} \text { is d-expensive }))) \\
& \quad(-\mathrm{er} \\
& \quad(-\mathrm{er}(\mathrm{B} \text { is d-expensive })(\mathrm{C} \text { is d-expensive })) \\
& \quad(-\mathrm{er}(\mathrm{B} \text { is d-expensive })(\mathrm{A} \text { is d-expensive })))
\end{aligned}
$$

Japanese comparatives have no generalized quantifier operator, so that such restriction does not apply.

\section{Differential Numerals}

Before concluding this paper, I would like to mention how to deal with differential numerals, as in (40) and (41).

$$
\begin{array}{ccc}
\begin{array}{c}
\text { Andy-ga } \\
\text {-NOM }
\end{array} & \mathrm{kg} \text { futot-tei-ru. } \\
\text { get.fat-PROG-PRES }
\end{array}
$$

'Andy is $5 \mathrm{~kg}$ fatter than the contextually provided degree.'

$$
\begin{aligned}
& \text { Andy-ga Bill-yori } 5 \mathrm{~kg} \text { futot-tei-ru. } \\
& \text {-NOM -than get.fat-PROG-PRES- }
\end{aligned}
$$

'Andy is $5 \mathrm{~kg}$ fatter than Bill.'

There are several ways to go, and I would like to suggest two possibilities. One idea is that ED wipes off the existential quantifier biding the difference-denoting degree variable. In this case, movement of the numeral to the top of the sentence must be assumed. (40), for example, is computed as in (42).

(42) a. $5 \mathrm{~kg}$ [Andy is fat-pos]

b. $\quad 5 \mathrm{~kg}\left[\exists \mathrm{d}_{2}\left[\uparrow \delta_{\mathrm{fat}}(\mathrm{a})=\mathrm{d}_{c}+\mathrm{d}_{2}\right]\right]$

c. $\quad 5 \mathrm{~kg}\left[\lambda \mathrm{d}_{2}\left[\uparrow \delta_{\text {fat }}(\mathrm{a})=\mathrm{d}_{c}+\mathrm{d}_{2}\right]\right]$

d. $\quad \uparrow \delta_{\text {fat }}(\mathrm{a})=\mathrm{d}_{c}+5 \mathrm{~kg}$

The other is to assume that difference-denoting numerals such as $5 \mathrm{~kg}$ are translated into a CCP containing a degree discourse marker, $\uparrow \mathrm{d}_{2}=5 \mathrm{~kg}$, via lexical translation rules, rather than type shifting such as $d=>c c$. This CCP is dynamically conjoined to the matrix clause and then the discourse marker is bound by an existential quantifier, as in (43). I leave the choice open here. 


$$
\underline{\exists} \mathrm{d}_{2}\left[\uparrow \delta_{\mathrm{fat}}(\mathrm{a})=\mathrm{d}_{c}+\mathrm{d}_{2} \underline{\Lambda} \uparrow \mathrm{d}_{2}=5 \mathrm{~kg}\right]
$$

\section{Concluding remarks}

To the best of my knowledge, the syntax/semantics of stacking comparatives has never been discussed, and in fact no language with stacking comparatives has been reported so far. In this paper, I showed that Japanese has stacking comparatives and their semantic properties are accounted for in the framework of dynamic semantics.

There is at least one serious problem in the present analysis, however. As extensively argued by Schwarzschild and Wilkinson 2002, Heim 2006, Gajawsky 2008, and Schwarzschild 2008 among others, the maximal operator in the than-clause does not provide the adequate value when QPs are involved in it. The definition of clausal yori that I proposed also contains the max operator, so it should be revised somehow. Furthermore, I have noticed that besides the presence or absence of entailment, phrasal and clausal complements of yori have different truth conditions when QPs are involved. (44a) and (44b) are minimal pairs with respect to the complement of yori. The former is interpreted just like the English counterpart Andy is fatter than most women (are). On the other hand, (44b) is interpreted as true only in the situation where most women are fat, and Andy is fatter than the fattest woman among those women.

$$
\begin{aligned}
& \text { a. [hotondo-no-josee]-yori Andy-ga futot-tei-ru. } \\
& \text { most-GEN-woman-than -NOM get.fat-PROG-PRES } \\
& \text { 'Andy is fatter than most women.' } \\
& \text { b. [hotondo-no-josee-ga futot-tei-ru]-yori } \\
& \text { most-GEN-woman-NOM get.fat-PROG-PRES } \\
& \text { Andy-ga futot-tei-ru. } \\
& \text {-NOM get.fat-PROG-PRES } \\
& \text { '(lit.) Andy is fat than most women are fat.' }
\end{aligned}
$$

My definitions of DP-taking and clausal yori's do not work for either case. I leave this problem for future research. 
Japanese comparatives are conjuncts

\section{Appendix}

Definitions of dynamic semantics (Chierchia 1995)

Domains: For each type $a, \mathrm{D}_{a}$ are the denotations of entities of type $a$.

a. $\mathrm{D}_{e}=\mathrm{U}_{e}$, where $\mathrm{U}_{e}$ is the domain of individuals.

b. $\mathrm{D}_{t}=\{0,1\}$

c. $\mathrm{D}_{d}=\mathrm{U}_{d}$, where $\mathrm{U}_{d}$ is the domain of degrees.

d. $\mathrm{D}_{<a, b>}=\mathrm{D}_{b} \mathrm{Da}$

e. $\mathrm{D}_{<s, a>}=\mathrm{D}_{a} \Omega$, where $\Omega$ is the set of all possible assignments to discourse markers.

Interpretation functions:

a. $\|\wedge \alpha\|^{\mathrm{g}, \omega}=\lambda \omega^{\prime}\|\alpha\|^{\mathrm{g}, \omega^{\prime}}$

That is, $\left\|{ }^{\wedge} \alpha\right\|^{\mathrm{g},{ }^{\omega}}$ is that function $\mathrm{h}$ in $\mathrm{D}_{a} \Omega$ such that for any $\omega^{\prime} \in \Omega$, $\mathrm{h}\left(\omega^{\prime}\right)=\|\alpha\|^{\mathrm{g}, \omega^{\prime}}$

b. $\left\|{ }^{\vee} \alpha\right\|^{\mathrm{g},{ }^{\omega}}=\|\alpha\|^{\mathrm{g}, \omega}(\omega)$

Context Change Potentials (CCPs) : $\uparrow \phi=\lambda \mathrm{p}\left[\phi \wedge{ }^{\vee} \mathrm{p}\right]$ of type $c c=<<s, t>, t>$

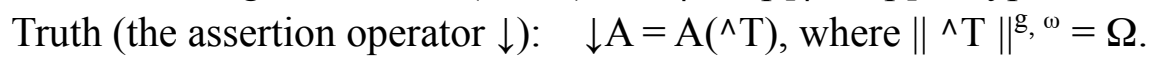

Dynamic conjunction and existential quantification:
a. $\mathrm{A} \underline{\wedge} \mathrm{B}=\lambda \mathrm{p}\left[\mathrm{A}\left(\mathrm{B}\left({ }^{\wedge} \mathrm{p}\right)\right)\right]$
b. $\exists x A=\lambda p \exists x[A(p)]$

\section{References}

Barker, Chris. 2002. The dynamics of vagueness. Linguistics and Philosophy 25. 1-36.

Beck, Sigrid, Toshiko Oda, \& Koji Sugisaki. 2004. Parametric variation in the semantics of comparison: Japanese vs. English. Journal of East Asian Linguistics 13. 289-344.

Bhatt, Rajesh \& Shoichi Takahashi 2008. Reduced and unreduced phrasal comparatives. ms. University of Massachusetts, Amherst and University of Tokyo, to appear in Natural Language and Linguistics Theory.

Brasoveanu, Adrian. 2008. Comparative correlatives as anaphora to differentials. In T. Friedman and S. Ito (eds.), Semantics and Linguistic Theory (SALT) 18, 126-143. Ithaca, NY: CLC.

Bresnan, Joan. 1973. Syntax of the comparative clause construction in English. Linguistic Inquiry 4. 275-343.

Chierchia, Gennaro. 1995. Dynamics of meaning: anaphora, presupposition and the theory of grammar. Chicago, IL: Chicago University Press.

Dekker, Paul. 1993. Existential disclosure. Linguistics and Philosophy 16. 561-587. 
Hayashishita, J.-R. 2007. Izyoo(ni)- and gurai-comparatives: comparisons of deviation in Japanese. Gengo Kenkyu 132. 77-109.

Hayashishita, J.-R. 2009. Yori-comparatives: a reply to Beck et al. (2004). Journal of East Asian Linguistics 18. 65-100.

Heim, I. 2006. Remarks on comparative clauses as generalized quantifiers. ms. MIT.

Gajewski, Jon. 2008. More on quantifiers in comparative clauses. In T. Friedman and S. Ito (eds.), Semantics and Linguistic Theory (SALT) 18, 340-357. Ithaca, NY: CLC.

Kennedy, Christopher. 2007. Vagueness and grammar: the semantics of relative and absolute gradable adjectives. Linguistics and Philosophy 30. 1-45.

Klein, Ewan. 1991. Comparatives. In Arinim von Stechow and Dieter Wunderlich (eds.) Semantik: Ein internatiionales Handbuch der zeigenössischen Forschung. 673-691, New York, NY: Walter de Gruyter.

Schwarzchild, Roger. 2008. The semantics of comparatives and other degree constructions. Language and Linguistics Compass 2. 308-331.

Schwarzschild, Roger \& Karina Wilkinson. 2002. Quantifiers in comparatives: a semantics of degree based on intervals. Natural Language Semantics 10. $1-41$.

von Stechow, Arinim. 1984. Comparing semantic theories of comparison. Journal of Semantics 3. 1-77.

Takeo Kurafuji

College of Law

Ritsumeikan University

56-1, Tojiin, Kitamachi, Kita-ku

Kyoto 603-8577

JAPAN

kurafuji@fc.ritsumei.ac.jp 